\title{
Evidéncias de um silêncio: um estudo sobre Graciliano Ramos e Tiago Santana
}

Evidences of a silence: a study on Graciliano Ramos and Tiago Santana

Fábio José Santos de Oliveira

Universidade Federal de Sergipe, São Cristóvão, SE, Brasil

Resumo: Nosso ensaio objetiva analisar quatro fotografias do volume 0 chão de Graciliano, organizado em 2006 pelo jornalista Audálio Dantas e pelo fotógrafo Tiago Santana, de quem são as imagens. As quatro fotografias escolhidas são lidas em confronto com Vidas secas (1938), romance do escritor homenageado em 0 chão de Graciliano. Utilizando dois conceitos de Roland Barthes sobre a fotografia (studium e punctum), estabelecemos os pontos-chave na análise que pretendemos, a saber: "a separação mesmo na proximidade" e "o silêncio entre as personagens".

Palavras-chave: Literatura Comparada. Literatura e Fotografia. Graciliano Ramos. Tiago Santana.

Abstract: In this essay we intend to analyze four images from $O$ chão de Graciliano [Graciliano's ground], a volume organized by the journalist Audálio Dantas and the photographer Tiago de Santana. These four chosen photographs are ridden in comparison with Vidas secas [Barren lives] (1938), novel by the writer honoree in O chão de Graciliano. We departed from two concepts of Roland Barthes on photography (studium and punctum) to establish the two key-points of our analysis: "distance although proximity" and "silence among the characters".

Keywords: Comparative Literature. Literature and Photography. Graciliano Ramos. Tiago Santana.

“[...] el fotógrafo o el cuentista se ven precisados a escoger y limitar una imagen o un acaecimiento que sean significativos, que no solamente valgan por sí mismos, sino que sean capaces de actuar en el espectador o en el lector como una especie de apertura, de fermento que proyecta la inteligencia y la sensibilidad hacia algo que va mucho más allá de la anécdota visual o literaria contenidas en la foto o en el cuento." Julio Cortázar, "Algunos aspectos del cuento“ 
FábioJoséSantos de Oliveira

Em 2003, aconteceu no Sesc Pompeia, em São Paulo, uma exposição comemorativa aos 110 anos de nascimento do escritor Graciliano Ramos e aos 70 anos de publicação de Caetés, seu primeiro livro. Esse projeto tinha curadoria de Audálio Dantas e ensaio fotográfico de Tiago Santana. Três anos depois, o sucesso do projeto renderia um livro, o chão de Graciliano, cujos textos de abertura ficariam a cargo do jornalista Joel Silveira e do próprio Audálio Dantas. É dessa publicação de 2006 que retiramos as fotografias para análise em nosso ensaio, a partir do confronto com Vidas secas, romance de Graciliano Ramos publicado em 1938. As fotos de O chão de Graciliano registram cenas dos lugares onde o autor de São Bernardo viveu ou por onde simplesmente passou. Cidades como Quebrangulo, terra natal de Graciliano, ou Palmeira dos Índios, de onde foi prefeito. As fotografias que encorpam essa publicação de 2006 registram, para além da paisagem em seus aspectos de natureza e habitação, também o cotidiano da gente simples, moradora da mesma terra onde Graciliano cresceu e viveu boa parte de sua vida. A lente de Tiago Santana tem a característica de apresentar não apenas o produto histórico-social de seu modelo fotográfico, mas também e em geral um olhar que distorce os ângulos do ver, isto é, que procura mostrar o imprevisto e o inabitual. Se avaliarmos no mínimo dos detalhes, perceberemos que sua fotografia é menos "jornalística" que "literária". E ao tomarmos dois planos alheios à natureza material da fotografia, o fazemos para demonstrar o que parece ser seu projeto pessoal, a um só tempo sociológico e artístico, senão mais artístico que sociológico. A recorrência dos temas e a aparente sujeição do olhar à materialidade do vivido (ou melhor, aos instantâneos do dia a dia de uma gente simples) parecem, à primeira vista, declarar que sua obra estaria sujeita a um imediatismo de informação e a uma pura projeção empática. O que temos a dizer é que sua máquina está entrincheirada entre uma ética pessoal e a necessidade de transcender a obviedade dos temas. Afinal: "Although the camera is an observation station, the act of photographing is more than passive observing" (SONTAG, 2008 , p. 12)․․ Daí, a nosso ver, a riqueza do conteúdo que Tiago Santana tem a expor, tem a nos mostrar: "Car pour Tiago Santana

\footnotetext{
1 "Embora a câmera seja um espaço de observação, o ato de fotografar supera o observar passivo."
} 
il s'agit toujours et partout de suggérer, de montrer des indices, de donner les pistes d'un récit qui trouvera sa forme finale ailleurs. Aussi fondamentales que le centre sont les zones de fuite " (MANET, $2003, \mathrm{~s} / \mathrm{p})^{2}$. Ou, segundo o reconhecimento do próprio fotógrafo:

\footnotetext{
Procuro encontrar uma forma de contar histórias com sutileza, estranheza, mistério. Busco na singularidade daquelas pessoas, em seus lugares, olhares e paisagens que me inquietam e me impulsionam a fotografar, como se quisesse não só desvelar algo, mas também criar (apud PERSICHETTI, 2001, p. 1).
}

Quanto a Vidas secas, trata-se de um clássico, de uma obra já assentada nos domínios da literatura brasileira. Esse pequeno romance de Graciliano, ao qual Antonio Candido classifica como "políptico ou rosácea - qualquer coisa de nítido e primitivo [...]" (1992, p. 46), é hoje um livro sobre o qual tudo de mais importante parece já ter sido dito. "Neste romance, o estilo peculiar de Graciliano, isto é, a concisão, precisão e sugestão dos vocábulos, chega à sua forma mais depurada, revelando bem a já tão comentada 'magreza'de sua prosa" (COELHO, 1964, p. 33-34). Geralmente enquadrado no Regionalismo de 1930, Vidas secas rompe com a lógica de uma literatura militante (no sentido mais panfletário do termo). Vidas secas é um livro que se propõe a visão do social e a análise não apressada dos detalhes que o envolvem. O determinismo presente em Os sertões de Euclides da Cunha (tratando de assunto parecido) se perde na leitura comparado com as aparas históricas de Vidas secas e sua visada (vazia de cientificismos) sobre os constituintes de uma realidade social. Assim é que se vislumbram nos treze capítulos do romance (como que amarrados em costura) as dificuldades materiais e simbólicas do vaqueiro Fabiano, de sinha Vitória (sua esposa), do menino mais velho e do menino mais novo (filhos do casal) e da cachorrinha Baleia, cujo capítulo o escritor montaria os demais.

o que trataremos aqui, nessa relação literário-fotográfica, se desenvolverá a partir de detalhes presentes em alguns momentos específicos de 0 chão de Graciliano e Vidas secas, ou melhor, de Vidas secas e $O$ chão de Graciliano. Nessa ordem. Se fôssemos nos contentar com a afinidade de

2. "Pois para Tiago Santana, trata-se sempre e em toda parte de sugerir, de mostrar índices, de dar as pistas de uma narrativa que encontrará sua forma final em outro lugar. Tão fundamentais quanto o centro são as zonas de fuga."
Evidências de um silêncio: um estudo sobre Graciliano Ramos e Tiago Santana 
FábioJoséSantos de Oliveira assunto, a maior parte das imagens da publicação de 2006 nos serviria com tranquilidade, já que elas lidam sobre matéria também tratada por Graciliano, sua fonte primeira. Aliás, se vistas em separado dessa inter-relação, algumas dessas fotografias perderiam muito dos aspectos que tentaremos abordar. $\mathrm{O}$ que estudaremos aqui é um tanto específico, e o será porque nosso critério de estabelecimento das semelhanças far-se-á, como dissemos, segundo o crivo do detalhe, e por detalhe queremos dizer o que se mostra, no geral, apenas depois de tomarmos conhecimento do assunto em fotografia ou no texto literário: “[...] a sociedade se move, também, a partir do indizível e do invisível. Resta saber se no verbalizável há indícios do indizível, se na fala há evidências do silêncio. Ou se no visível há indícios do invisível" (MARTINS, 2013, p. 27). utilizados por Roland Barthes em La chambre claire (A câmera clara). São eles: studium (indicativo do tipo de sociedade à qual a fotografia se refere: seu contexto, suas marcas cotidianas, sua cultura, em suma) e punctum (aspecto de tratamento subjetivo, ou seja, o que de pontual se destacaria dos valores do studium a ponto de marcar quem observa a fotografia). Nesse sentido, e vez ou outra, transparecem-nos, de dentro do studium do corpus fotográfico de Tiago Santana, determinadas imagens correlativas ao universo literário de Graciliano. E é esse ponto (o punctum) que costura um e outro texto (quer fotográfico, quer literário), nosso mote aqui. Podemos perceber isso pela "distância na proximidade" e pelo "silêncio" inquietante das personagens da narrativa em questão, bem como das figuras humanas de certas fotos de 0 chão de Graciliano. Eis aí o momento em que certos trechos de ambas as obras se encontram profundamente.

Começamos por expor um trecho de "Mudança”, capítulo inicial de Vidas secas:

Miudinhos, perdidos no deserto queimado, os fugitivos agarraram-se, somaram as suas desgraças e os seus pavores. $O$ coração de Fabiano bateu junto do coração de sinha Vitória, um abraço cansado aproximou os farrapos que os cobriam. Resistiram à fraqueza, afastaram-se envergonhados, sem ânimo de afrontar de novo a luz dura, receosos de perder a esperança que os alentava (RAMOS, 2000, p. 13). 
Como sabemos, o momento de abertura de Vidas secas dá-se já com a retirada da família que protagoniza a obra. Fabiano, sinha Vitória e os seus perambulam sem destino, em fuga da seca que já tinha devastado a região de onde vinham, e à procura de um lugar melhor onde viver. Estão, nesse momento, fatigados da caminhada, quase faltos de ânimo e de coragem para continuar a marcha. A perspectiva de cada um deles é, pois, de cansaço e de desânimo. Estão esgotados, por isso abertos ao acalento, a um mínimo de amparo que seja. Os corpos pendem e se lançam de leve num abraço. Mas isso dura pouco, porque no raciocínio de ambos qualquer sentimentalismo ali seria sinal de fragilidade, precisavam ser duros para suportar a rigidez do tempo e da natureza:

Mesmo os seus retirantes - em Vidas secas - são seres de quem a realidade (Camus, talvez, dissesse destino) retirou até mesmo a voz: o silêncio do livro, um silêncio tão abrasador quanto o sol sertanejo ou argelino, que é sobretudo icônico em relação ao que se quer caracterizar, indicia o nível de impossibilidade de recomposição desse homem partido e solitário (BARBOSA, 1983, p. 36).

Nesse fragmento de Vidas secas, são as adversidades que os impedem de estar mais perto além da mera aproximação dos corpos. No capítulo "Inverno", a situação lhes é bem mais favorável, só que a separação persiste. Estão de novo amontoados, dessa vez perto da trempe da cozinha da tapera abandonada, que se tornara moradia deles vencidas as agruras daquela fuga inicial. Agora não há mais o medo da seca; pelo contrário, chove, e chove muito. 0 medo que resta é o de que as águas inundem a casa, e assim mesmo isso só passa pela cabeça de sinha Vitória. Fabiano, não, está alegre, satisfeito, faz planos, conta estórias em voz alta. Os meninos discutem entre si tentando entender o que o pai lhes narra. Baleia parece incomodada com o barulho que seu dono faz. E aí temos o retrato de momento e do grupo:

\footnotetext{
Na verdade nenhum deles prestava atenção às palavras do outro; iam exibindo as imagens que lhes vinham ao espírito, e as imagens sucediam-se, deformavam-se, não havia meio de dominá-las. Como os recursos de expressão eram minguados, tentavam remediar a deficiência falando alto (RAMOS, 2000, p. 63-64) .
}

Evidências de
um silêncio: um
estudo sobre
Graciliano
Ramose Tiago
Santana 
Estão juntos, próximos, lado a lado, mas cada qual estaciona em seu próprio devaneio em voz alta. Às vezes, o véu desse sonho de olhos abertos se rasga e eis que travam um pequeno contato; no entanto, esse contato, não raras vezes, gera ou é gerado por algum desentendimento, algum desacordo entre eles. Afinal, não estavam acostumados ao diálogo: “Ordinariamente a família falava pouco" (RAMOS, 2000, p. 11).

FábioJoséSantos de Oliveira

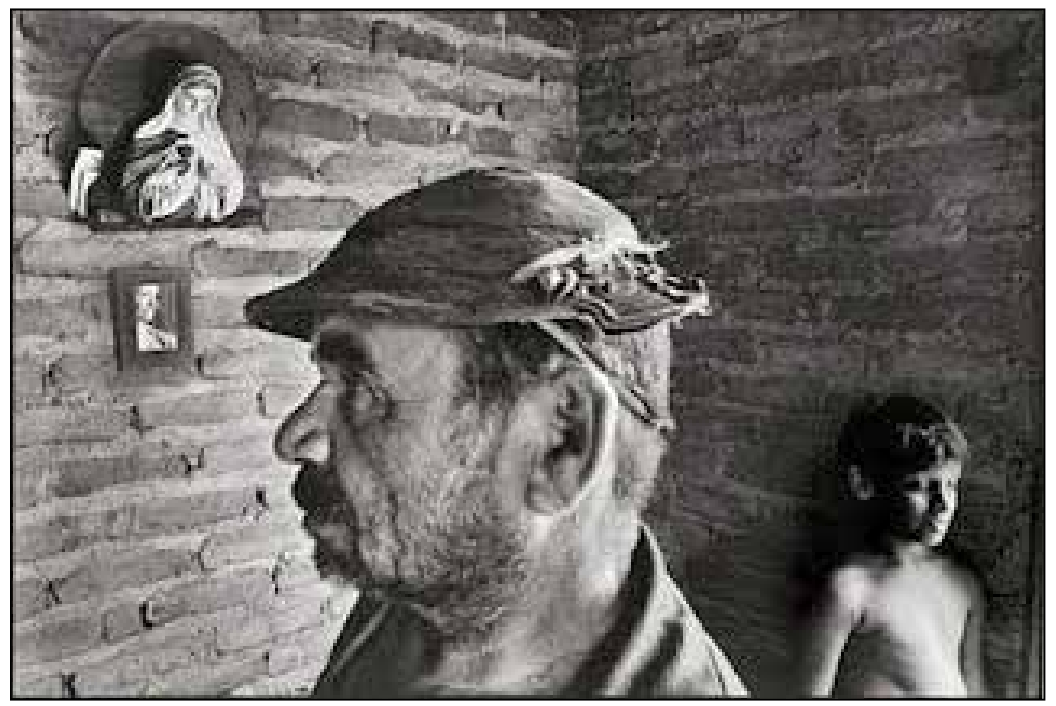

Fig. 1: Tiago Santana (1966), o chão de Graciliano, Caetés/PE, 2006.

Ao que vemos na fotografia acima (Fig. 1), tudo se passa no interior da casa. De imediato, inferimos a religiosidade da família (a partir da imagem de Nossa Senhora) e, em virtude do acabamento da parede, deduzimos a simplicidade da residência e da gente que vive aí. Mas isso, como já advertíamos, de maneira geral e há pouco, é apenas o dado mais imediato do conteúdo. O que nos inquieta mesmo é a separação de cada um dos componentes da família: pai, mãe e filho, cada qual ocupa seu lugar nessa sala e está imantado numa determinada posição. $O$ pai procura o lado esquerdo: parece atravessar o espaço. Mãe e filho estão virados no mesmo sentido, mas parados. O filho rente à parede e às costas do pai; a mãe, de quem só vemos o reflexo no espelho, parece esboçar um sorriso. 0 conjunto da cena retoma outras tantas de 0 chão de Graciliano: figuras humanas, aparentemente familiares entre si, são registradas em momentos que destacam sua proximidade e afastamento. Em todas essas cenas, o espaço entre os seres é preenchido por uma sensação de silêncio. Um silêncio de pessoas captadas em instantes de aparente alheamento ou separação. 
Se bem que Tiago Santana repete essa perspectiva em fotografias de outros projetos, como em Benditos (2000), o sertão dentro de mim (2010) e Céu de Luiz (2013). Além disso, como valores sociais, talvez as causas dessa separação e desse silêncio sejam (e provavelmente são) bem diferentes das que estão expostas em Vidas secas, só que, sendo este um material que se propõe uma homenagem a Graciliano, as aproximações em nível profundo se tornam também uma possibilidade.

De um modo geral, Tiago Santana traz em 0 chão de Graciliano fotografias de lugares diversos, pessoas diversas e circunstâncias também diversas. Porém, inevitavelmente e em algum momento, as cenas da literatura de Graciliano coincidem com uma ou outra imagem. Sem reconhecimento do fotógrafo, ficamos sem saber o quanto disso é proposital ou não. De qualquer forma, o pressuposto de que

Evidências de
um silêncio: um
estudo sobre
Graciliano
Ramose Tiago
Santana
coletânea, transparecem de imediato algumas dessas personagens criadas pelo escritor alagoano. Se o universo temático de suas obras se expande de tal modo, o mesmo procuramos nos detalhes da constituição interna da obra de um e outro: "Although there is a sense in which the camera does indeed capture reality, not just interpret it, photographs are as much an interpretation of the world as paintings and drawings are" (SONTAG, 2008, p. 6) ${ }^{3}$ :

E mais ainda, também imaginamos o momento em que a diferença de olhar mostraria também as diferenças num suposto "em-si" de cada fotógrafo: "Certa vez, Ortega [y Gasset] comentou que jamais duas câma-

3 "Embora haja um consenso de que a câmera captura de fato a realidade, e não a interpreta apenas, as fotografias são uma interpretação do mundo tanto quanto o são as pinturas e os desenhos." 
FábioJoséSantos de Oliveira

ras tiram a mesma fotografia de uma cena. À medida que o homem muda o seu ponto de vista, a realidade muda a sua natureza para ele" (SYPHER, 1980, p. 209). De fato, a informação de Ortega y Gasset diz muito sobre a materialidade da fotografia. No caso de Tiago Santana, o desafio se dá no cruzamento do corpo das realidades sociais e dessa perspectiva volátil presente em todo o projeto fotográfico. Vez ou outra, o campo polissêmico nele está em relevo, porque a imagem a que chegara tem mais a dizer do que o óbvio do tecido visual. Em confronto com Vidas secas, esse algo-a-mais encontra ampliado o seu horizonte. Como exemplo disso, podemos citar uma das fotos tiradas em Buíque/PE (Fig. 2).

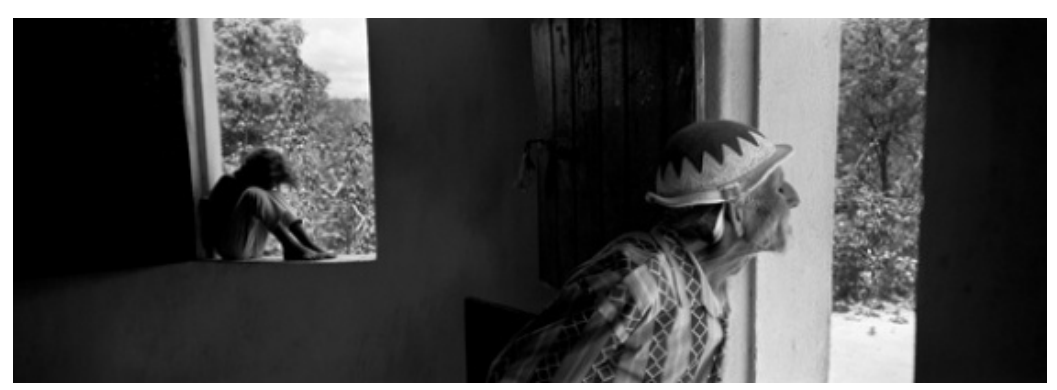

Fig. 2: Tiago Santana (1966), o chão de Graciliano, Buíque/PE, 2006.

Há algo que não se modifica no fato íntimo dessa foto: a separação entre o universo infantil e o do adulto (que tanto pode ser o pai ou o avô do garoto, não sabemos ao certo). Uma realidade como essa, demonstrando um paralelo de gerações, poderia ter sido captada de várias maneiras. No entanto, o que há de imutável aí, e isso faz parte também do estilo, foi a destreza (ou a fortuna) de Tiago Santana em captar de forma tão densa um instante em que esses dois universos, o infantil e o adulto, revelam muito de sua natureza. E aí temos: o menino curvado em seus próprios pensamentos, o adulto cuja preocupação é o que vem de fora da casa.

Antes de aprofundarmos o que vai exposto nessa fotografia, temos de particularizar as duas realidades aí presentes, isto é, tanto a infantil, quanto a adulta. Comecemos pela da criança e a partir de uma fotografia tirada em Quebrangulo/AL (Fig. 3). 


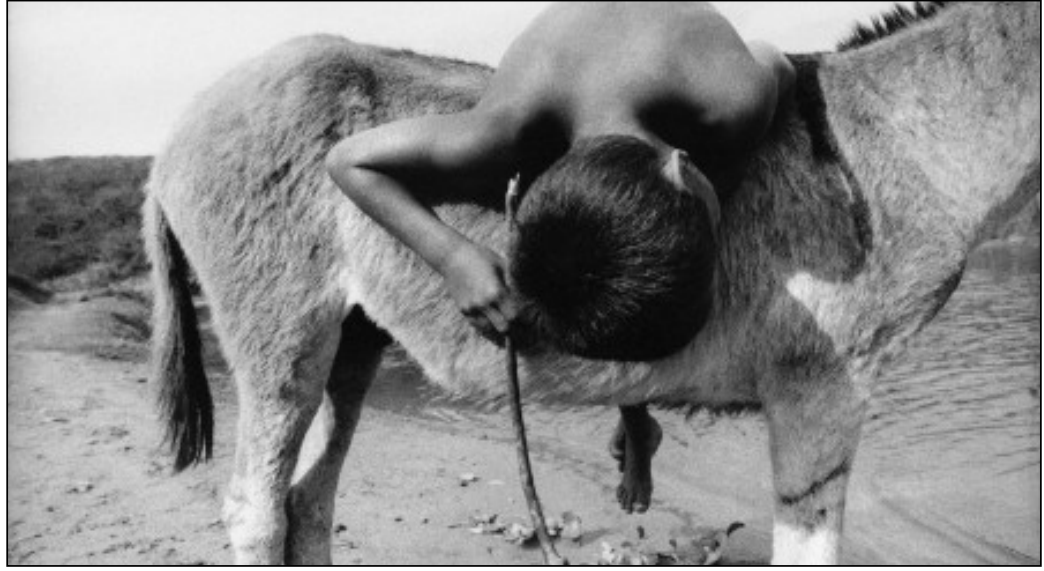

Fig. 3: Tiago Santana (1966), o chão de Graciliano, Quebrangulo/AL, 2006.

Como antes, não é a obviedade o que nos interessa, isto é, o garoto suspenso no dorso de um jumento. São os seus olhos que não vemos, seu rosto também escondido, ele próprio deitado de leve sobre o pelo do animal. Sua posição de devaneio, em suma. Naturalmente, não sabemos no que ele está pensando, sequer teríamos indícios disso, já que tudo em seu corpo (músculos relaxados, cabeça descansada, vareta quieta na mão) desenha o silêncio de quem está alheio à realidade exterior, porque mergulhado no fundo de si mesmo.

Todo o exposto nos conduz a algumas cenas de Vidas secas, relativas ou ao menino mais velho ou ao menino mais novo:

Uma das crianças aproximou-se, perguntou-lhe qualquer coisa. Fabiano parou, franziu a testa, esperou de boca aberta a repetição da pergunta. Não percebendo o que o filho desejava, repreendeu-o. O menino estava ficando muito curioso, muito enxerido. Se continuasse assim, metido com o que não era da conta dele, como iria acabar? (RAMOS, 2000, p. 20)

Deu-se aquilo porque sinha Vitória não conversou um instante com o menino mais velho. Ele nunca tinha ouvido falar em inferno. Estranhando a linguagem de sinha Terta, pediu informações. Sinha Vitória, distraída, aludiu vagamente a certo lugar ruim demais, e como o filho exigisse uma descrição, encolheu os ombros. [...]

Aí sinha Vitória se zangou, achou-o insolente e aplicou-lhe um cocorote (RAMOS, 2000 , p. 54).

[...] foi puxar a manga do vestido da mãe, desejando comunicar-se
Evidências de um silêncio: um estudo sobre Graciliano Ramos e Tiago Santana 
com ela. Sinha Vitória soltou uma exclamação de aborrecimento, e, como o pirralho insistisse, deu-lhe um cascudo. [...] Apesar de ter medo do pai, chegou-se a ele devagar, esfregou-se nas perneiras, tocou as abas do gibão. As perneiras, o gibão, o guarda-peito, as esporas e o barbicacho do chapéu maravilhavam-no.

Fabiano desviou-o desatento, entrou na sala e foi despojar-se daquela grandeza (RAMOS, 2000, p. 48).

FábioJoséSantos de Oliveira

Os dois primeiros fragmentos se referem a algo acontecido com o filho mais velho; sua curiosidade, no caso, sobre o sentido da palavra “inferno". Tendo uma dúvida, quis saná-la, recebendo em troca a aplicação de um cocorote. Depois de tudo, não resta ao garoto solução melhor que a de remoer consigo o motivo da violência, e suportar sozinho a dor que ela lhe causou. Já o filho mais novo tenta comunicar aos seus sua admiração acerca do que o pai é capaz de fazer montado numa rês brava. $O$ resultado que alcança não difere daquele do irmão:

Se na primeira passagem a condição da infância era trabalhada como um tecido de sonhos e desejos impotentes para alcançar as proezas do adulto, na segunda, a relação inverte-se. A criança que pergunta, a criança que exige da mãe a interpretação do símbolo (o que é inferno?), supera, na verdade, os limites da gente grande. Fabiano e sinha Vitória, prensados entre o menino e o muro da própria inconsciência, reagem com um silêncio evasivo e, afinal, irritados pelo espinho da interpelação, desafogam-se com a agressão física (BOSI, 1988, p. 16).

A direção do pensar dos garotos difere em ambos, mas o lucro de suas inquietações não diverge substancialmente. Estão os dois no devaneio de uma ideia, de uma curiosidade. Não desejam mais do que isso: transmitir o que se sente (menino mais novo), apagar um pouco da ignorância (menino mais velho). Por fim, ambos se veem relegados a enfrentar sozinhos suas angústias infantis. Mesmo na relação de um com o outro o apoio desvanece, haja vista os interesses particulares à idade de cada um. Resta-lhes como paliativo se isolarem quando já não há conforto, quando, apesar da balbúrdia interior, o silêncio é o que vigora. É bem verdade que há ocasiões em que eles encontram proximidade e regozijo. Não ignoramos isso. Se damos destaque a esses instantes de tensão e 
deslocamento é em respeito ao foco que o próprio Graciliano estabelece nos capítulos que levam o nome de cada um dos garotos. Também é verdade que não podemos afirmar que o garoto da fotografia de Tiago Santana tenha enfrentado constrangimentos semelhantes e por isso se quedou entretido em devaneios. Possivelmente, não, tendo em vista que os contextos diferem. O que nos sobra (e isso é o que mais nos importa) é a semelhança, além da que está na temática do garoto, do isolamento e do silêncio que o significante visual da fotografia nos concede.

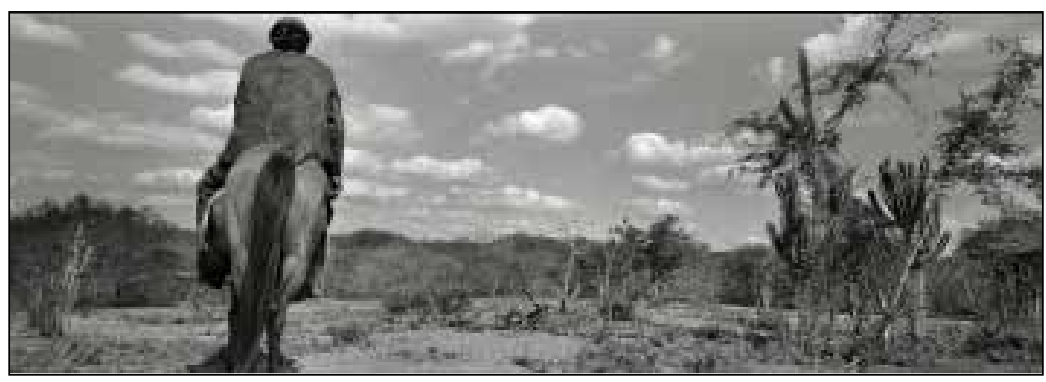

Evidências de um silêncio: um estudo sobre Graciliano Ramos e Tiago Santana

Fig. 4: Tiago Santana (1966), o chão de Graciliano, Buíque/PE, 2006.

Quanto à realidade do adulto acerca da qual prometemos uma prévia discussão, tomaremos por base uma fotografia de Buíque/PE (Fig. 4): imagem retratando um céu ensolarado e cheio de nuvens de um dia seco, uma realidade de caatinga e um vaqueiro que defronta essa paisagem. A foto pode ser dividida no equilíbrio de duas partes, cujos centros estariam, da esquerda para a direita, o vaqueiro em seu cavalo e um amontoado de cactos grandes. Homem e um pedaço de vegetação se encontram lado a lado. Adiante se mostra um retalho de caminho que dá acesso ao restante da vegetação cerrada. Por estar montado em seu cavalo, munido dos apetrechos de serviço e, principalmente, de costas, uma informação logo ganha força de verdade: a de que é para dentro da mata cerrada que esse homem se encaminhará. $O$ vaqueiro está parado, mas toda a gestualidade contemplativa que ele encarna como que prenuncia os movimentos exigidos por seu trabalho, movimentos a serem possivelmente executados daí a pouco tempo. Tanto é assim que outras fotografias de 0 chão de Graciliano mostram vaqueiros às carreiras e enfrentando os garranchos de árvores de mesma vegetação. Esse vaqueiro tem no ambiente que contempla o locus de seu trabalho, e a este enfrenta toda vez que é preciso. No que resta, não sabemos quão profunda é a sua ligação com a natureza em volta nem se tem ou não apego a terra 
onde labuta: o que resulta de informação aí advém dos indícios que a fotografia nos oferece através do ângulo e do lado escolhidos para registro visual. Existe aí um homem que vê diante de si uma vegetação cerrada e tem os olhos fixos nela.

Como o sentido de nossa leitura das fotografias componentes de o chão de Graciliano acompanha o material de Vidas secas, como já ressaltamos, não podemos ignorar algumas semelhanças que a figura do vaqueiro Fabiano nos possibilita:

FábioJoséSantos de Oliveira
Agora Fabiano era vaqueiro, e ninguém o tiraria dali. Aparecera como um bicho, entocara-se como um bicho, mas criara raízes, estava plantado. Olhou as quipás, os mandacarus e os xique-xiques. Era mais forte que tudo isso, era como as catingueiras e as baraúnas. Ele, sinha Vitória, os dois filhos e a cachorra Baleia estavam agarrados à terra.

[...]

Vivia longe dos homens, só se dava bem com animais. Os seus pés duros quebravam espinhos e não sentiam a quentura da terra. Montado, confundia-se com o cavalo, grudava-se a ele. $\mathrm{E}$ falava uma linguagem cantada, monossilábica e gutural, que o companheiro entendia (RAMOS, 2000, p. 19).

Fabiano e os seus estavam agarrados a terra. E é na direção dela que ele, que eles caminham. Assim, durante a narrativa não raro encontramos uma ou outra comparação de cada uma das personagens a um animal diferente ou a um tipo específico de vegetação. $O$ próprio fragmento acima registra algumas dessas comparações: Fabiano era "como um bicho" e "como as catingueiras e as baraúnas": “Eles não tem, por assim dizer, 'mundo', e estão presos, como Baleia, à trela do mundo à volta, ao meio-ambiente" (ROSENFELD, 1994, p. 142). Essa interação simbolizadora de um caráter pessoal era, segundo a voz do narrador onisciente, um dos motivos de vulnerabilidade do vaqueiro face aos poderes e poderosos (o patrão, o soldado amarelo, os coletores de impostos da prefeitura, o dono da venda etc.): “Difícil pensar. Vivia tão agarrado aos bichos... Nunca vira uma escola. Por isso não conseguia defender-se, botar as coisas nos seus lugares" (RAMOS, 2000, p. 36). E as vidas secas do título do romance marcam, assim, um mundo de carências. Carências materiais e às 
vezes até simbólicas (como no caso do filho mais velho), carências de seres a quem tudo parece faltar: o pão de cada dia, uma vida digna, justiça pessoal e social.

É só no fim da narrativa que se lhes parece vislumbrar a possibilidade de algo novo. No capítulo intitulado "Fuga", Fabiano, sob ânimo de sinha Vitória, tenta reagir (e reage) contra esses elos de pendor naturalista: "Precisava fugir daquela vegetação inimiga" (RAMOS, 2000, p. 118). O realismo crítico de Graciliano nos apresenta, assim, um magote de seres esquecidos, articulando a esperança de dias melhores, de uma vida sem exploração e sem dificuldades materiais: "Sinha Vitória precisava falar. Se ficasse calada, seria como um pé de mandacaru, secando, morrendo. Queria enganar-se, gritar, dizer que era forte, e a quentura medonha, as árvores transformadas em garranchos, a imobilidade e o silêncio não valiam nada" (RAMOS, 2000, p. 118). E só aí vemos rompido consistentemente o silêncio ou a barulhada monossilábica de antes: esse é o momento de um passo à frente, de tentar olhar também para dentro de casa e não somente para a natureza que os rodeia. É o momento de juntar as vozes, acreditar num sonho e firmar-se numa esperança ${ }^{4}$.

Dito isso, podemos voltar à primeira fotografia de Buíque/PE (Fig. 2), a do garoto e do adulto. De certo, entre ambos se flagram elementos que os mostram distantes (ao menos afastados) um do outro, para além da idade, que é o primeiro elemento e o mais evidente deles. O interessante dessa fotografia é que o modo como as figuras humanas estão posicionadas e as ações que executam reforçam essas diferenças mais evidentes. Na imagem, garoto e adulto estão virados num mesmo sentido, mas encarnam preocupações totalmente distintas; por sinal, as mesmas que observávamos quando da leitura da figura 3 (o momento de devaneio) e da figura 4 (os olhos fixos na natureza). Aqui, essas realidades se conjugam. $O$ garoto, tendo a cabeça entre as pernas, está totalmente absorto em si; o adulto, ao contrário, tem os olhos abertos para o exterior. Os pés descalços do garoto parecem indicar que ele vai permanecer ainda algum tempo onde está e possivelmente não saia de casa tão em breve; já o adulto, tendo na cabeça o chapéu (objeto que em geral a população do campo não usa no interior de uma moradia), pa-

4. É bem verdade que a voz onisciente do narrador declara, já no final, que Fabiano e os seus sairiam daquele ambiente de dificuldades e entrariam em outro, dessa vez o urbano. Mas há em meio a essa ignorância das personagens uma esperança que as alimenta e as ajuda a romper os signos que as prendiam até então a uma série de problemas que demarcam bem o universo conteudístico de Vidas secas. 
FábioJoséSantos de Oliveira

rece assegurar suas próximas ações, a não ser que ele tenha acabado de entrar na residência. $O$ garoto domina a janela, lugar natural de mirada; só que não observa coisa alguma do que está do lado de fora, porque, como o menino mais velho e o menino mais novo, é dentro dele que as coisas se passam. Por sua vez, o adulto está encostado à porta, lugar de passagem; está ainda (ou já esteve) dentro da casa, mas seus olhos, como os de Fabiano, contemplam o que vêm do exterior. Afora isso, o vazio domina o centro da sala, enquanto os dois ocupam os extremos. Estão bem perto um do outro, mas as intenções particulares os separam: enquanto um se lança a seus próprios devaneios, o outro adere aos signos do entorno, da materialidade do dia a dia.

E como "Les ressemblances entre événements de détail ne doivent pas faire oublier les différences“5 (TADIÉ, 1990, p. 12), reiteramos que as aproximações estabelecidas entre Graciliano Ramos e Tiago Santana não excluem diferenças entre eles, até porque muito da carga social presente em Vidas secas (impotência e desamparo das personagens, microfísica do poder, deslocamento na sociedade etc.) se perde nessas fotografias de 2006, em virtude do próprio arranjo temático dessas e do senso de documentação empática da lente de Tiago de Santana. Já citamos uma ou outra ressalva ao longo do nosso texto, mas vale ainda um último exemplo: estaria esse adulto que ladeia a porta também "agarrado a terra", como no caso do vaqueiro Fabiano? Teria ele preocupações semelhantes, carências parecidas, desconfianças de tudo e de todos? Sobre isso, seria difícil uma resposta segura e contundente, tendoem vista a imanência da leitura das fotografias, que é o que temos em mãos no momento. Porém, como significantes, estão dadas aí as semelhanças entre literatura e fotografia, e dentro dessas semelhanças o possível de uma equivalência social. Se a equivalência existe já não importa tanto, porque a chave de tudo se liga ao diálogo transcendido a partir da mera substância do romance ou da fotografia. As equivalências que destacamos não são forçadamente sociais, ainda que o sejam num segundo momento: são estéticas, fazem parte do campo de constituição estrutural tanto do texto literário quanto do fotográfico. Uma estética que só exime a equiparação social de um juízo de verdade concreta, destacamos a tempo. Os demais referentes ligados à sociedade estão preservados aí, do contrário estaríamos estabelecendo um discurso

5. "As semelhanças entre eventos de detalhe não devem fazer esquecer as diferenças." 
no e a partir do vazio, algo com o qual não concordamos. À parte essas ressalvas (que não querem dizer sinal de negatividade, senão o específico de cada um), o chão de Graciliano se constitui como um projeto que dialoga bem com o escritor a quem se pretende homenagear.

É nesse diálogo de semelhanças estruturais que, outra vez referindo, nos surgem os dados de punctum do corpus em análise, a saber: a "distância mesmo na proximidade" e o "silêncio entre os seres". Um silêncio que domina a sala, que se insinua quando se está junto, mas em separado, que emudece a boca, mas que preserva ainda uma ruminação interior: "Se a linguagem implica silêncio, este, por sua vez, é o não-dito visto do interior da linguagem. Não é o nada, não é o vazio sem história. É o silêncio significante" (ORLANDI, 2007, p. 23). E essa perspectiva nos parece estar bem presente tanto em Graciliano Ramos quanto em Tiago Santana, tanto em Vidas secas quanto em O chão de Graciliano. Por sua vez, esses dados do punctum se assemelham também com os que caracterizam o studium, ou seja, o nível que aponta para os constituintes sociais e culturais do tema tratado, bem como para os possíveis embates dos autores em sua produção:

\footnotetext{
Reconnaître le studium, c'est fatalement rencontrer les intentions du photographe, entrer en harmonie avec elles, les approuver, les désapprouver, mais toujours les comprendre, les discuter en moi-même, car la culture (dont relève le studium) est un contrat passé entre les créateurs et les consommateurs (BARTHES, 2002, p. 810) ${ }^{6}$.
}

Graciliano Ramos e Tiago Santana são artistas de códigos diferentes, de gerações diferentes, de formas de pensar diferentes e mesmo de estéticas diferentes, mas se igualam não só porque desenvolvem uma mesma temática, como também pelo recorte estrutural que privilegia o invisível, ou melhor, o que parece explodir, mas se deixa revelar pelas entrelinhas. Aquilo que apontaria neles para uma simples coincidência temática se enriquece, portanto, pela valorização do recôndito, do detalhe, do punctum que dá acesso a um studium. E do punctum que nos marca (esse algo a mais, em detalhe, presente nessas obras de Tiago Santana e

6. "Reconhecer o studium é fatalmente encontrar as intenções do fotógrafo, entrar em harmonia com elas, aprová-las, desaprová-las, mas sempre compreendê-las, discuti-las em nós mesmos, pois a cultura (à qual compete o studium) é um contrato passado entre criadores e consumidores." 
FábioJoséSantos de Oliveira

Graciliano Ramos) encontramos elementos que se assemelham também quanto ao studium (de ordem sócio-cultural, como já mencionado). Ambos os artistas, portanto, igualam-se nas obras apresentadas pelo tema e pelos detalhes, pelo dito e pelo não-dito, pelo evidente e pelo implícito. Depois que interpretamos esses índices, o mundo registrado por eles parece de uma obviedade que espanta, e tanto mais porque, até momentos imediatamente anteriores à interpretação, tudo era, como dissemos, instâncias do latente, do sub-reptício. É bem verdade que a matéria com que lidamos aparenta uma obviedade tácita, dado o alardeamento discursivo sobre os temas tratados. O que tentamos expor aqui se refere, repetimos, àquilo que se esconde na matéria profunda, que revela muito mais do que o susto do óbvio, aquilo que, em outras palavras, desloca um tema aparentemente chavão e o situa dentro do campo onde, como dado estrutural, se encaixa socialmente. Eis o momento de também nos concentrarmos para prestar atenção às evidências de um silêncio que, como punctum, deixa em seguida uma tensão no ar e depois nos pede escuta, insistentemente.

\section{REFERÊNCIAS BBLIOGRÁFICAS}

BARBOSA, João Alexandre. A modernidade no romance. In: FILHO, Domício Proença (Org.). o livro do Seminário. São Paulo: L R Editores, 1983.

BARTHES, Roland. La chambre claire : note sur la photographie. In: . Euvres complètes : tome V (1977-1980). France : Seuil, 2002.

BOSI, Alfredo. Céu, inferno. In: _. Céu, inferno: ensaios de crítica literária e ideológica. São Paulo: Ática, 1988.

CANDIDO, Antonio. Ficção e confissão. Rio de Janeiro: Ed. 34, 1992.

COELHO, Nelly Novaes. Solidão e luta em Graciliano Ramos. In:

Tempo, solidão e morte. São Paulo: Imprensa Oficial do Estado, 1964.

DANTAS, Audálio; SANTANA, Tiago. 0 chão de Graciliano. Fortaleza/CE, São Paulo/SP: Tempo d'imagem, 2006. 
MANET, Eduardo. "Sertão" : Photographies de Tiago Santana. France: Photo Poche Société, 2003.

MARTINS, José de Souza. A epifania dos pobres da terra. In: MAMMÌ, Lorenzo ; SCHWARCZ, Lilia Moritz (Org.). 8 x fotografia. São Paulo: Companhia das Letras, 2008.

Evidências de um silêncio: um Sociologia da Fotografia e da imagem. 2 ed. São Paulo: Contexto, 2013. estudo sobre Graciliano Ramos e Tiago

ORLANDI, Eni Puccinelli. As formas do silêncio: no movimento do Santana sentidos. 6 ed. Campinas/SP: Editora da Unicamp, 2007.

PERSICHETTI, Simonetta. Sertão em olhar curtido pelo tempo. 0 Estado de S. Paulo, Caderno de Cultura, São Paulo, 31 maio 2001.

RAMOS, Graciliano. Vidas secas. 80 ed. Rio de Janeiro, São Paulo: Record, 2000.

ROSENFELD, Anatol. Letras e leituras. Org. Nanci Fernandes e Jacó Guinsburg. São Paulo: Perspectiva, 1994.

SONTAG, Susan. On Photography. London: Penguin Modern Classics, 2008.

SYPHER, Wylie. Do rococó ao cubismo. Trad. Maria Helena Pires Martins. São Paulo: Perspectiva, 1980.

TADIÉ, Jean-Yves. Le roman au XXe siècle. Paris: Pierre Belfond, 1990.

Recebido em 11 de setembro de 2015 Aceito em 11 de dezembro de 2015 
